\title{
AVALIAÇÃO TÉCNICA E DE CUSTOS DE PODA MANUAL E SEMIMECANIZADA EM PLANTIOS DE Pinus taeda
}

\author{
Felipe Martins de Oliveira ${ }^{1}$, Eduardo da Silva Lopes ${ }^{2}$, Jorge Roberto Malinovski $^{3}$, \\ Rafael Henrique da Silva ${ }^{4}$, Carla Krulikowski Rodrigues ${ }^{4}$
}

${ }^{1}$ Eng. Florestal, M. Sc. em Ciências Florestais, UNICENTRO, Irati-PR, Brasil - felipemartins@ @lorestal.eng.br ${ }^{2}$ Eng. Florestal, Dr., Depto. de Engenharia Florestal, UNICENTRO, Irati, Paraná, Brasil - eslopes@ irati.unicentro.br ${ }^{3}$ Eng. Florestal, Dr., Depto. de Ciências Florestais, UFPR, Curitiba, Paraná, Brasil - malinovski@ ufpr.br

${ }^{4}$ Bolsista de Iniciação Científica, UNICENTRO, Irati, Paraná, Brasil - rafaique11@ @otmail.com; carlakr@ gmail.com

Recebido para publicação: 10/05/2012 - Aceito para publicação: 10/11/2012

\begin{abstract}
Resumo
O objetivo desta pesquisa foi realizar uma avaliação técnica e de custos das atividades de poda manual e semimecanizada em plantios de Pinus taeda L., visando gerar informações para o aumento da produtividade, melhoria da qualidade e redução dos custos de produção. A pesquisa foi conduzida em uma empresa prestadora de serviços florestais, localizada na região do Norte Pioneiro, Estado do Paraná. Foram estudadas as atividades de podas executadas a 2,5 m; 4,0 m e 5,0 m de altura. A avaliação técnica consistiu em um estudo de tempos e movimentos, determinando a produtividade, a eficiência operacional e a qualidade das operações, verificando a presença de tocos de galhos e injúrias no lenho. A análise de custos foi feita por meio da determinação dos custos operacionais e de produção. Os resultados mostraram que a poda manual apresentou menor produtividade em relação ao método semimecanizado, porém proporcionou melhor qualidade do trabalho em termos de injúrias no lenho das árvores. Apesar do maior custo de produção, a execução das podas mais altas pelo método semimecanizado tornou-se viável técnica e economicamente devido à melhor qualidade do trabalho em relação à presença de tocos de galhos e possíveis benefícios ergonômicos aos trabalhadores.

Palavras-chave: Produtividade; custo; desrama e silvicultura.
\end{abstract}

\begin{abstract}
Technical and cost evaluation of manual and semi-mechanized pruning in plantations of Pinus taeda. The objective of this research was to conduct technical and cost analysis of pruning in Pinus taeda L. planted forests by semi-mechanized and manual methods to increase productivity, improve the quality and reduction of costs. The research was conducted in a forest service company, located in the State of Parana, Brazil. There was studied the pruning to $2.5 \mathrm{~m}, 4.0 \mathrm{~m}$ and $5.0 \mathrm{~m}$ high. The technical evaluation consisted of a time and motion study, determining the productivity, operational efficiency and the quality of activities verifying the presence of branch stumps and injuries in the wood. The cost analysis was done by determining operating and production costs. The results showed that manual pruning had lower productivity compared to the semi-mechanized method, provided even better quality of work over terms apparent injuries on wood. Though even higher production cost, the implementation of pruning higher by semi-mechanized methods becomes more technical and economically, caused by better quality work in relation to the branch stumps and possible ergonomics benefits to workers.
\end{abstract}

Keywords: Productivity; cost; pruning and silviculture.

\section{INTRODUÇÃO}

O setor florestal brasileiro apresenta grande importância para a sociedade em termos econômicos, sociais e ambientais, possuindo, atualmente, uma área ocupada por plantios da ordem de 6,5 milhões de hectares com espécies do gênero Pinus e Eucaliptus. A região Sul se destaca pelos plantios de Pinus, concentrando $83 \%$ dos plantios do país, devido às condições edafoclimáticas favoráveis e a localização dos principais centros processadores (ABRAF, 2012). Entretanto, para a formação de uma floresta produtiva e a obtenção de uma madeira de melhor qualidade que atenda às exigências das 
indústrias é necessário a realização de algumas práticas silviculturais nas florestas de pinus, com destaque para a poda ou desrama.

Segundo Schneider et al. (1999), a existência de elevada densidade de árvores em um povoamento florestal favorece à desrama natural, porém ocasiona uma diminuição do crescimento em diâmetro, que de acordo com o manejo adotado, poderá ser desfavorável à condução dos povoamentos. Além disso, a desrama natural é um processo lento, onde, muitas vezes, os galhos mortos permanecem aderidos ao tronco, afetando negativamente a qualidade da madeira. Por isso, a poda ou desrama artificial surge como uma técnica capaz de melhorar as propriedades físicas e mecânicas da madeira serrada, valorizando a produção florestal.

Segundo Seitz (1995) e Paiva (2008), a poda ou desrama é uma prática silvicultural importante dentro do processo produtivo, objetivando a retirada de galhos das árvores, reduzindo a quantidade e o tamanho dos nós e possibilitando a produção de madeira de melhor qualidade. Esta prática permite correções na forma do tronco, evitando-se bifurcações e diminuindo-se a conicidade, bem como maior proteção contra incêndios florestais e facilidade para marcação de árvores para desbaste (QUIRINO, 1991; MONTAGNA et al., 1993). Além disso, é importante ressaltar sua importância nos plantios de algumas espécies de Pinus que não possuem desrama natural.

A execução desta atividade permite ainda obter produtos de maior valor agregado, evitando os defeitos como a presença de nós em madeira serrada, laminada, faqueada, etc (HOSOKAWA et al. 1998). Paiva (2008) e Schilling (1996) dizem ainda que, como os nós presentes na madeira são remanescentes dos galhos não removidos na época adequada, os mesmos ocasionam a descontinuidade de suas fibras, tornando as peças fracas e impróprias para determinados usos comerciais, provocando um aspecto estético indesejável e efetando negativamente a sua qualidade físico-mecânica.

Para Schneider et al. (1999) é importante ainda destacar que, em termos operacionais, a poda é realizada pelas empresas florestais, por meio de métodos manuais ou semimecanizados, com o envolvimento de grande quantidade de trabalhadores, não existindo outro método, seja biológico ou genético, em que as técnicas silviculturais sejam capazes de alcançar o mesmo êxito no aumento do valor comercial e da qualidade da madeira. Portanto, em função da importância desta atividade silvicultural, do grande contingente de mão de obra envolvida e da expansão prevista para o setor florestal nos próximos anos, torna-se necessária a realização de estudos que possibilitem conhecer a real contribuição das atividades silviculturais, e auxiliem na melhoria dos processos produtivos e redução dos custos de produção.

O objetivo deste estudo foi realizar uma avaliação técnica e de custos das operações de poda manual e semimecanizada em plantios de Pinus taeda L., visando subsidiar o planejamento das atividades e a otimização do sistema produtivo.

\section{MATERIAL E MÉTODOS}

\section{Área de estudo}

A pesquisa foi conduzida em uma empresa prestadora de serviços florestais, localizada na Região Norte Pioneiro do Estado do Paraná, entre as coordenadas geográficas $24^{\circ} 01^{\prime} 58^{\prime \prime}$ S e $50^{\circ} 27^{\prime 2} 28^{\prime \prime}$ WG e altitude de 776 metros. O clima predominante na região, segundo classificação de Köopen, é subtropical úmido mesotérmico - Cfa, com temperatura média anual de $21^{\circ} \mathrm{C}$ e precipitação média anual entre 1.200 e $1.400 \mathrm{~mm}$.

Os povoamentos da empresa eram constituídos de Pinus taeda L., localizados em terrenos com relevo suave a ondulado, espaçamento $3 \times 2 \mathrm{~m}$ e idades de 5,8 e 10 anos, por ocasião da realização da primeira, segunda e terceira poda, respectivamente, não tendo sido realizados desbastes nas áreas estudadas. O Índice de Bulbo Úmido e Termômetro de Globo (IBUTG) médio do local de estudo era de $22,3{ }^{\circ} \mathrm{C}$ durante a coleta dos dados.

\section{População e amostragem}

A pesquisa foi realizada com base em uma amostra composta por quatro trabalhadores florestais experientes e devidamente treinados para a execução das podas manual e semimecanizada. Os trabalhadores estudados possuíam idade média de 36 anos, peso médio de 76,5 kg e estatura média de $166 \mathrm{~cm}$.

\section{Área experimental}

A área experimental possuía características semelhantes em relação ao relevo e o povoamento, sendo amostradas 960 árvores na primeira poda, onde cada trabalhador realizou a poda de 120 árvores em 
cada método. Na segunda poda, foram amostradas 1.600 árvores, sendo 200 árvores por trabalhador dentro de cada método. Por fim, na terceira poda foram amostradas 2.000 árvores, onde cada trabalhador realizou a poda de 250 árvores dentro de cada método de trabalho.

\section{Atividades estudadas}

Foram estudadas as atividades de primeira poda executada até $2,5 \mathrm{~m}$ de altura, segunda poda até 4,0 $\mathrm{m}$ e terceira poda até $5,0 \mathrm{~m}$ pelos métodos manual e semimecanizado (Figura 1).

A poda manual foi realizada com uso de um serrote com lâmina curva, recomendada para a remoção de galhos de 2 a $15 \mathrm{~cm}$ de diâmetro (SEITZ, 1995), enquanto na poda semimecanizada usou-se motopodas da marca Stihl ${ }^{\circledR}$, sendo o modelo KA 85R na primeira poda e o modelo HT 75 na segunda e terceira podas.
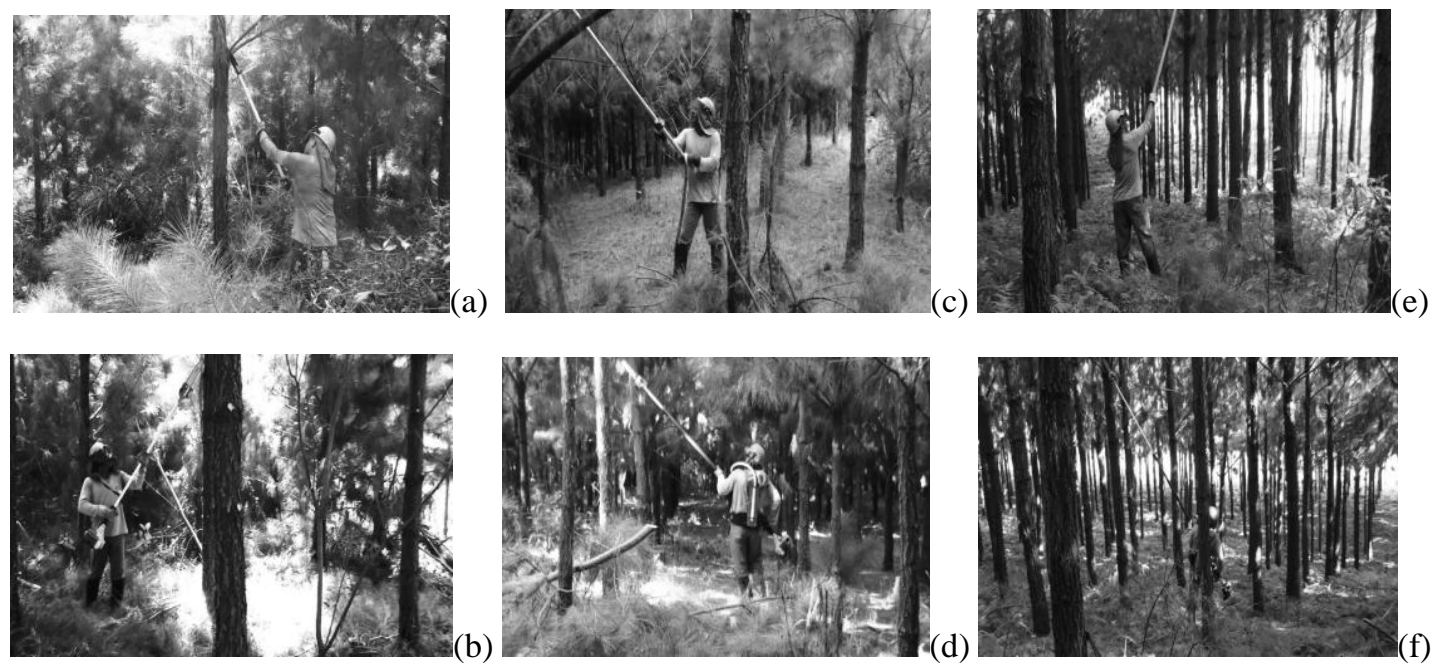

Figura 1. Primeira poda manual (a) e semimecanizada (b), segunda poda manual (c) e semimecanizada (d) e terceira poda manual (e) e semimecanizada (f).

Figure 1. First manual (a) and semimechanized (b) pruning, second manual (c) and semimechanized (d) pruning and third manual (e) semimechanized (f) pruning.

As características do serrote de poda e das motopodas utilizadas nas diferentes podas estudadas são descritas na tabela 1 .

Tabela 1. Características do serrote de poda e motopodas utilizados no estudo.

Table 1. Characteristics of the pruning saw and motopodas used in the study.

\begin{tabular}{lcccccc}
\hline \multirow{2}{*}{ Poda } & $\begin{array}{c}\text { Altura } \\
(\mathbf{m})\end{array}$ & $\begin{array}{c}\text { Comprimento(*) } \\
(\mathbf{m})\end{array}$ & $\begin{array}{c}\text { Peso } \\
(\mathbf{k g})\end{array}$ & Modelo & $\begin{array}{c}\text { Comprimento(**) } \\
(\mathbf{m})\end{array}$ & $\begin{array}{c}\text { Peso(***) } \\
(\mathbf{k g})\end{array}$ \\
\hline $1^{\mathbf{a}^{\mathrm{a}}}$ & 2,5 & 1,8 & 1,5 & KA 85R & 2,0 & 5,9 \\
$2^{\mathrm{a}}$ & 4,0 & 3,0 & 2,2 & HT 75 & 3,0 & 8,6 \\
$3^{\text {a }}$ & 5,0 & 4,4 & 2,9 & HT 75 & 3,8 & 8,6 \\
\hline$*:$ com lâmina e cabo; **: com a haste telescópica no comprimento adequado para a determinada poda; ***: com o conjunto de
\end{tabular}

corte acoplado e os tanques de combustível e óleo de corrente.

\section{Análise Técnica}

A análise técnica foi realizada para a determinação da produtividade, eficiência e qualidade das operações de poda nos dois métodos avaliados. Para tal, foi realizado um estudo de tempos e movimentos por meio da cronometragem de tempo contínuo, onde a leitura do cronômetro foi feita no ponto de medição referente à atividade parcial recém-concluída. Foi utilizado um cronômetro centesimal, prancheta e formulários específicos. 
O ciclo de trabalho das operações de poda manual e semimecanizada foi subdivido em atividades parciais, conforme apresentado na tabela 3.

Tabela 2. Descrição das atividades de poda manual e semimecanizada.

Table 2. Description of the manual and semimechanized pruning activities.

\begin{tabular}{lcc}
\hline Operação & Atividades Parciais & Descrição \\
\hline $\begin{array}{l}\text { Poda } \\
\text { manual }\end{array}$ & Poda propriamente dita & Eliminação dos galhos das árvores até determinada altura. \\
\cline { 2 - 3 } & Deslocamento & Deslocamento do trabalhador no interior do talhão. \\
\cline { 2 - 3 } $\begin{array}{l}\text { Poda } \\
\text { semimecanizada }\end{array}$ & Pausas & Interrupções pessoais. \\
\cline { 2 - 3 } & Peda propriamente dita & Eliminação dos galhos das árvores até determinada altura. \\
\cline { 2 - 3 } & Abastecimento & Abastecimento da motopoda com combustível e óleo lubrificante \\
& Manutenção & Realização da afiação da corrente e pequeno reparo na motopoda. \\
\cline { 2 - 3 } & Pausas & Interrupções pessoais. \\
\cline { 2 - 3 }
\end{tabular}

A produtividade das operações de poda foi determinada por meio da contagem do número de árvores podadas em relação ao tempo total consumido, por meio da seguinte expressão:

$$
\mathrm{Pp}=\frac{\mathrm{Na}}{\mathrm{T}}
$$

Em que: $\mathrm{Pp}=$ produtividade da poda (árvores/hora);

$\mathrm{Na}=$ número de árvores podadas

$\mathrm{T}=$ tempo consumido, em horas.

A eficiência operacional foi obtida pela razão entre o tempo produtivo e o tempo total consumido para realização das operações, por meio da seguinte expressão:

$$
\mathrm{Ef}=\frac{\mathrm{Tp}}{\mathrm{Tt}}
$$

Em que: $\mathrm{Ef}=$ eficiência operacional;

$\mathrm{Tp}=$ Tempo efetivo consumido para realização da atividade, em horas;

$\mathrm{Tt}=$ Tempo total consumido para realização da atividade, em horas.

A qualidade das operações de poda foi verificada por meio da determinação da quantidade de tocos de galhos e de injúrias presentes no lenho das árvores em relação à quantidade de galhos podados por árvore.

Neste estudo foi empregada uma amostragem sistemática contemplando $10 \%$ do total das árvores podadas por trabalhador, sendo amostrada uma árvore a cada 10 podadas na linha de plantio. Para a medição do comprimento dos tocos foi utilizada uma régua graduada em milímetros, sendo a qualidade da poda determinada conforme a classificação a seguir:

- Comprimento de toco $(\mathrm{T} \leq 1 \mathrm{~cm})$ : aceitável

- Comprimento de toco $(1<\mathrm{T} \leq 2 \mathrm{~cm})$ : aceitável com ressalvas

- Comprimento de toco $(T>2 \mathrm{~cm})$ : não aceitável

\section{Análise de Custos}

A análise de custos da atividade de poda em ambos os métodos de trabalho foi realizada por meio da determinação do custo operacional e do custo de produção. O custo operacional foi obtido pela 
determinação dos custos fixos, variáveis e administrativos, utilizando a metodologia proposta por Harry et al. (1991) e adaptado nesta pesquisa, enquanto o custo de produção foi obtido pela divisão do custo operacional pela produtividade da ferramenta ou equipamento.

\section{Análise Estatística}

As variáveis produtividade e qualidade entre os métodos de trabalho foram comparadas pelo teste t para dados pareados, ao nível de 5\% de significância. Os valores de produtividade dentro de cada método de trabalho foram submetidos à Análise de Variância (ANOVA) no delineamento inteiramente casualizado e, quando necessário, as médias foram comparadas pelo teste de Duncan, ao nível de $5 \%$ de significância.

\section{RESULTADOS E DISCUSSÃO}

\section{Análise Técnica}

A distribuição percentual média dos ciclos de trabalho das atividades de primeira, segunda e terceira podas em ambos os métodos estudados são mostrados na figura 2. Como pode ser visto, em todas as situações estudadas, a atividade de poda propriamente dita ocupou o maior tempo do ciclo de trabalho, principalmente no método semimecanizado, com 76, 79 e $73 \%$ do tempo total na execução da primeira, segunda e terceira poda, respectivamente, evidenciando a maior eficiência operacional deste método.

É importante destacar o elevado tempo de pausas realizadas pelos trabalhadores na execução do método manual, ocupando 21,23 e $25 \%$ do ciclo de trabalho na primeira, segunda e terceira poda, respectivamente. Tal resultado ocorreu, provavelmente, devido ao maior esforço físico exigido pelo método manual em relação ao semimecanizado, levando os trabalhadores a fazerem pausas mais frequentes durante o trabalho, contribuindo para a redução da eficiência operacional.

No método semimecanizado foi possível constatar que, os trabalhadores normalmente aproveitam os períodos de realização das atividades de manutenção e abastecimento do equipamento durante a jornada de trabalho para fazer as pausas de recuperação, reduzindo com isso, o tempo despendido com pausas extras propriamente dita, e consequentemente, aumentado à eficiência do trabalho. Além disso, deve-se ressaltar que, na terceira poda, o maior tempo requerido para as pausas ocorreu, provavelmente, também pela maior dificuldade do manuseio da máquina na execução da poda em maiores alturas.

Na tabela 3 são apresentados os valores médios de produtividade e eficiência operacional nas atividades de poda em ambos os métodos de trabalho.

Em relação à primeira poda executada pelo método manual, a produtividade média foi de 56,5 árvores/he, com eficiência operacional média de $70 \%$, enquanto no método semimecanizado foi de 63,4 árvores/he e eficiência operacional média de $76 \%$, com variação de 10,9\% entre os métodos estudados, porém, sem diferença estatística significativa $(\mathrm{P}<0,05)$.

$\mathrm{Na}$ segunda poda realizada pelo método manual, a produtividade média foi de 40,17 árvores/he, enquanto no semimecanizado foi de 67,15 árvores/he, com diferença significativa de $40,1 \%$ entre os métodos $(\mathrm{P}<0,05)$. A maior produtividade observada no método semimecanizado pode ser explicada pelo fato da maior altura dos galhos podados favorecerem o uso da motopoda na execução da operação. Tal situação ficou ainda mais evidente ao analisar a terceira poda, onde foi possível verificar um ganho significativo de produtividade da ordem de $64 \%$ favorável ao método semimecanizado, cuja produtividade média foi de 84,5 árvores/he.

Ao analisar a produtividade e a eficiência operacional das diferentes podas em ambos os métodos de trabalho, verificou-se que, em relação à poda manual, não houve diferença significativa entre os valores observados. Em relação ao método semimecanizado, a produtividades média na primeira, segunda e terceira poda foram, respectivamente, 63,4, 67,2 e 84,5 árvores/he, com diferença significativa entre a primeira e terceira poda, ao nível de $5 \%$ de significância. Tal resultado evidenciou a maior eficiência do método semimecanizado na realização das podas mais altas e a viabilização da mecanização nestas condições de trabalho. 


\section{Primeira Poda Manual}

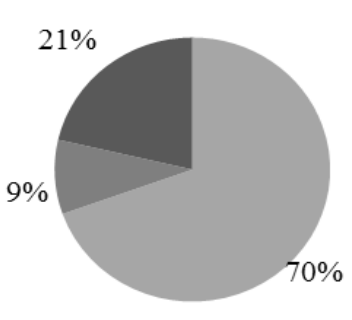

- Poda

- Deslocamento

- Pausas

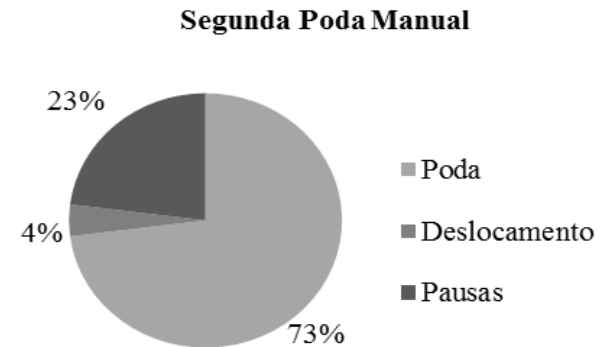

Terceira Poda Manual

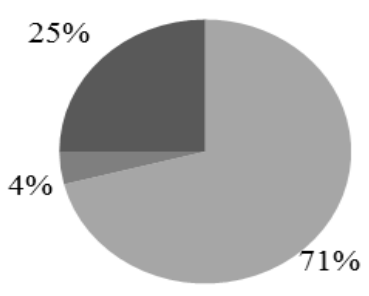

$$
\text { — Poda }
$$

- Deslocamento

- Pausas

\section{Primeira Poda Semimecanizada}

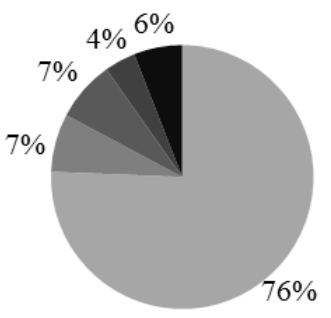

- Poda

Deslocamento

- Pausas

- Abastecimento

- Manutenção

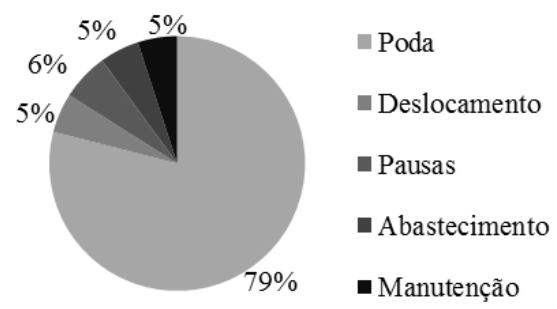

Terceira Poda Semimecanizada

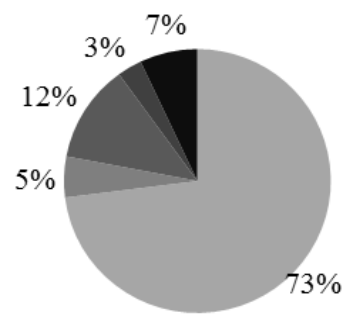

- Poda

- Deslocamento

- Pausas

- Abastecimento

- Manutenção

Figura 2. Composição percentual média do ciclo operacional da primeira, segunda e terceira poda nos métodos estudados.

Figure 2. Average percent composition of the operational cycle of the first, second and third pruning in the methods studied.

Tabela 3. Produtividade média das operações de poda nos métodos estudados.

Table 3. Mean productivity of the pruning operations over methods studied.

\begin{tabular}{|c|c|c|c|c|c|}
\hline Método & $\begin{array}{l}\text { Tempo efetivo } \\
\text { (he })\end{array}$ & $\begin{array}{l}\text { Tempo total } \\
\text { (h) }\end{array}$ & $\begin{array}{l}\text { Produtividade efetiva } \\
\qquad(\operatorname{arv} / \mathrm{h} e)\end{array}$ & $\begin{array}{c}\text { Produtividade real } \\
\quad(\text { arv/h) }\end{array}$ & $\begin{array}{c}\text { Eficiência } \\
\text { operacional } \\
(\%)\end{array}$ \\
\hline \multicolumn{6}{|c|}{$1^{\text {a }}$ Poda } \\
\hline $\mathrm{M}$ & $2,35 \pm 0,81$ & $3,37 \pm 0,99$ & $56,46 \pm 21,52$ & $37,84 \pm 10,65$ & $70 \pm 18$ \\
\hline SM & $1,91 \pm 0,17$ & $2,50 \pm 0,30$ & $63,38 \pm 6,22$ & $48,46 \pm 6,12$ & $76 \pm 5$ \\
\hline \multicolumn{6}{|c|}{$2^{\mathrm{a}}$ Poda } \\
\hline $\mathrm{M}$ & $5,03 \pm 0,41$ & $6,91 \pm 0,67$ & $40,17 \pm 3,33$ & $29,27 \pm 2,86$ & $73 \pm 1$ \\
\hline SM & $3,05 \pm 0,35$ & $3,86 \pm 0,51$ & $67,15 \pm 7,53$ & $52,88 \pm 5,99$ & $79 \pm 6$ \\
\hline \multicolumn{6}{|c|}{$3^{\mathrm{a}}$ Poda } \\
\hline $\mathrm{M}$ & $4,54 \pm 0,35$ & $6,49 \pm 0,77$ & $51,66 \pm 7,19$ & $36,82 \pm 7,20$ & $71 \pm 6$ \\
\hline SM & $3,02 \pm 0,39$ & $4,18 \pm 0,61$ & $84,50 \pm 10,87$ & $61,99 \pm 10,71$ & $73 \pm 6$ \\
\hline
\end{tabular}

M: Manual; SM: Semimecanizado;*: significativo a 5\%; ns: não significativo a 5\%; he: Tempo efetivamente trabalhado descontadas as interrupções operacionais e não operacionais (horas); h: Tempo total trabalhado incluindo as interrupções operacionais e não operacionais (horas). 
Em todas as podas realizadas, houve maior quantidade de tocos com comprimento abaixo de um centímetro, mostrando que a qualidade da atividade foi atendida neste aspecto (figura 3). É possível ainda verificar que, com exceção da primeira poda executada pelo método manual, na medida em que aumentou a altura de execução da poda, houve aumento da presença de tocos de galhos, principalmente no método manual. Tal fato pode estar relacionado à maior dificuldade de apoio do serrote junto ao tronco da árvore, fato não observado no método semimecanizado.
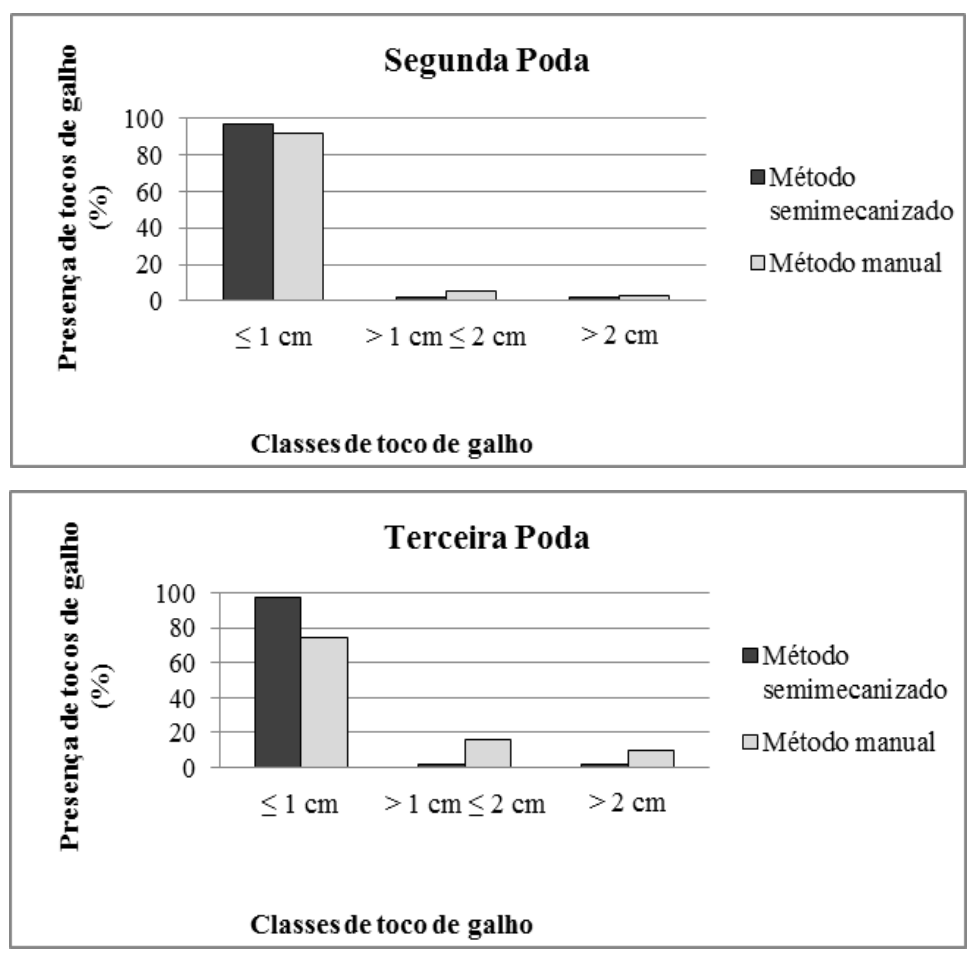

Figura 3. Distribuição percentual média de tocos de galhos.

Figure 3. Average percentage distribution of the branches stumps.

A tabela 4 é apresentada os percentuais médios de tocos de galhos podados inferiores a um centímetro e de injúrias aparentes no lenho das árvores, ressaltando tratar-se da classe aceitável em termos de qualidade e que representou mais de $70 \%$ dos galhos podados. Como pode ser visto, em relação à presença de tocos de galhos, o método semimecanizado apresentou uma melhor qualidade, comprovado pelo menor percentual de tocos de galhos com comprimento acima de $1 \mathrm{~cm}$, situação que poderá evitar danos à qualidade da madeira a ser produzida. Por outro lado, verifica-se que houve uma maior ocorrência de injúrias aparentes no lenho durante a execução de todas as podas pelo método semimecanizado, ocasionado pela maior dificuldade de manuseio do equipamento e visualização dos galhos por parte dos trabalhadores, principalmente durante a execução das podas mais altas. Entretanto, este problema poderá ser corrigido no futuro por meio do treinamento dos trabalhadores na execução do trabalho.

É importante ressaltar que, em relação a ambos os parâmetros de qualidade houve diferença significativa entre os métodos de poda estudados $(\mathrm{P}<0,05)$, confirmando a influência do maior grau de mecanização na execução desta atividade.

\section{Análise de Custos}

Os custos operacionais e de produção da primeira, segunda e terceira poda em ambos os métodos estudados são apresentados na tabela 5. Como pode ser visto, em todas as podas estudadas, houve um maior custo operacional e de produção do método semimecanizado, explicado pelo maior custo fixo dado à depreciação da máquina e o maior salário do trabalhador. 
Tabela 4. Percentual médio de tocos de galhos e injúrias aparente na madeira.

Table 4. Mean percentage of branches stumps and apparent injuries on wood.

\begin{tabular}{|c|c|c|c|c|}
\hline Método & $\begin{array}{c}\text { Galhos } \\
\text { podados }\end{array}$ & $\begin{array}{l}\text { Média de galhos } \\
\text { podados por árvore }\end{array}$ & $\begin{array}{c}\text { Percentual de tocos } \\
\text { de galhos } \leq 1 \mathrm{~cm}(\%)\end{array}$ & $\begin{array}{l}\text { Injúrias médias } \\
\text { aparentes no lenho }\end{array}$ \\
\hline \multicolumn{5}{|c|}{$1^{\mathrm{a}}$ poda } \\
\hline Manual & 980 & 20 & 79,0 & $14(1 \%)$ \\
\hline Semimecanizado & 1072 & 22 & 95,0 & $58(5 \%)$ \\
\hline \multicolumn{5}{|c|}{$2^{\mathrm{a}}$ poda } \\
\hline Manual & 836 & 10 & 92,0 & $14(2 \%)$ \\
\hline Semimecanizado & 1094 & 14 & 96,0 & $76(7 \%)$ \\
\hline \multicolumn{5}{|c|}{$1^{\mathrm{a}}$ poda } \\
\hline Manual & 772 & 8 & 74,5 & $22(3 \%)$ \\
\hline Semimecanizado & 839 & 8 & 97,5 & $61(7 \%)$ \\
\hline
\end{tabular}

*: significativo a 5\%; M: manual; SM: semimecanizado.

Além disso, verifica-se que o custo de produção no método semimecanizado foi superior ao método manual em todas as podas, com valores $79,9 \% ; 24,0 \%$ e $26,6 \%$ para a primeira, segunda e terceira poda, respectivamente, com diferença significativa entre o método manual e semimecanizado para a primeira e segunda poda $(\mathrm{P}<0,05)$.

Tabela 5. Produtividade, custo operacional e de produção da poda manual e semimecanizada.

Table 5. Productivity, operating and production cost of manual and semi-mechanized pruning.

\begin{tabular}{|c|c|c|c|c|}
\hline Método & $\begin{array}{c}\text { Produtividade } \\
\text { (ha/he) }\end{array}$ & $\begin{array}{c}\text { Eficiência Operacional } \\
(\%)\end{array}$ & $\begin{array}{c}\text { Custo Operacional } \\
\text { (R\$/he) }\end{array}$ & $\begin{array}{c}\text { Custo de Produção } \\
\text { (R\$/ha) }\end{array}$ \\
\hline \multicolumn{5}{|c|}{$1^{\mathrm{a}}$ poda } \\
\hline Manual & 0,03 & 70,0 & 8,45 & $249,52(*)$ \\
\hline Semimecanizado & 0,04 & 76,0 & 17,07 & 448,91 \\
\hline \multicolumn{5}{|c|}{$2^{\mathrm{a}}$ poda } \\
\hline Manual & 0,02 & 73,0 & 8,43 & $349,93(*)$ \\
\hline Semimecanizado & 0,04 & 79,0 & 17,48 & 433,91 \\
\hline \multicolumn{5}{|c|}{$3^{\mathrm{a}}$ poda } \\
\hline Manual & 0,03 & 71,0 & 8,45 & $272,65(\mathrm{~ns})$ \\
\hline Semimecanizado & 0,05 & 73,0 & 17,50 & 345,24 \\
\hline
\end{tabular}

*: significativo a 5\%; ns: não significativo a 5\%.

Diante dos resultados obtidos, foi possível constatar a viabilidade técnica e de custos do método semimecanizado, principalmente na execução da segunda e terceira podas. Apesar do maior custo de produção observado, ocasionado pelos maiores custos de aquisição e operação do equipamento e salário dos trabalhadores, o método apresentou maior produtividade e uma melhor qualidade das árvores podadas em relação aos tocos de galhos, podendo acarretar em maior agregação no valor da madeira. Além disso, ressalta-se o fato do método semimecanizado poder propiciar em benefícios aos trabalhadores do ponto de vista ergonômico, contribuindo para uma melhor postura e menor esforço físico na execução do trabalho.

\section{CONCLUSÕES}

As análises realizadas permitem concluir que:

- O elevado percentual de pausas realizadas pelos trabalhadores na execução da poda manual pode estar relacionado ao maior esforço físico exigido pela atividade, o que acarretou menor produtividade e eficiência operacional.

- O método de poda semimecanizado proporcionou melhor qualidade do trabalho devido ao menor percentual de tocos de galhos fora do padrão, porém mostrou a necessidade de treinamento e maior tempo de adaptação dos trabalhadores com o equipamento para a melhoria da qualidade em relação às injúrias no lenho das árvores. 
- Em todas as podas estudadas, o custo de produção foi maior no método semimecanizado, ocasionado pelos maiores custos de depreciação da máquina e de salários dos trabalhadores.

- Apesar do maior custo de produção, o método semimecanizado mostrou-se viável na execução das podas mais altas, possibilitando ganhos de produtividade, qualidade da madeira e benefícios aos trabalhadores do ponto de vista ergonômico.

\section{AGRADECIMENTOS}

Ao CNPq pelo apoio financeiro e a empresa pela cessão da área para a realização do estudo.

\section{REFERÊNCIAS}

ASSOCIAÇÃO BRASILEIRA DE PRODUTORES DE FLORESTAS PLANTADAS (ABRAF). Anuário Estatístico 2012. 2012. p. 149.

HARRY G. G.; FONTES J. M.; MACHADO C. C.; SANTOS S. L. Análise dos efeitos da eficiência no custo operacional de máquinas florestais. In: I SIMPÓSIO BRASILEIRO SOBRE EXPLORAÇÃO E TRANSPORTE FLORESTAL, 1, Belo Horizonte, 1991. Anais... Belo Horizonte: SIF/DEF, 1991. p. 57 75.

HOSOKAWA, R. T.; MOURA, J. B.; CUNHA, U. S. Introdução ao manejo e economia de florestas. Curitiba: UFPR, 1998. 162 p.

MONTAGNA, R. G.; FERNANDES, P. S.; ROCHA, F. T.; FLORSHEIM, S. M. B.; COUTO, H. T. Z. Influência da desrama artificial sobre o crescimento e a densidade básica da madeira de Pinus elliottii var. elliottii. Série Técnica IPEF, Piracicaba, v. 9, n. 27, p. 35 - 46, 1993.

PAIVA, H. N. Florestas de eucalipto: implantação e manutenção. In: SEMANA DE ESTUDOS FLORESTAIS, 10. 2008, Irati. Anais... Irati: UNICENTRO/DEF, 2008. CD-ROM.

QUIRINO, W. F. Influência da desrama e do desbaste na qualidade da madeira. Brasília: IBAMA, DIRPED, 1991. $12 \mathrm{p}$.

SCHILLING, A. C. Influência da desrama sobre a qualidade da madeira de primeiro desbaste de Pinus elliottii Engelm. 73 f. Dissertação (Programa de Pós-Graduação em Engenharia Florestal), Universidade Federal de Santa Maria, Santa Maria, 1996.

SCHNEIDER, P. R.; FINGER, C. A. G.; HOPPE, J. M. Efeito da intensidade de desrama na produção de Pinus elliottii Engelm., implantado em solo pobre, no estado do Rio Grande do Sul. Ciência Florestal. Santa Maria, RS, v. 9, n. 1, 1999, p. 35 - 46.

SEITZ, R. A. Manual de Poda de Espécies Arbóreas Florestais. Curitiba: FUPEF, 1995. 56 p. 
